Helwar Figueroa Salamanca

Profesor Universidad Pedagógica Nacional

\title{
¿UNIVERSIDADES PÚBLICAS EN COLOMBIA? UNA MIRADA HISTÓRICA ${ }^{1}$
}

...efectivamente, nos encontramos en un terreno en el que son tantas las verdades que hay que decir -verdades terribles, tormentosas, imperdonables-, que desde luego no faltará contra nosotros el odio más puro. En ciertas ocasiones será solamente el furor el que sugerirá una risa incómoda. Basta con que pienses en las inmensas escuadras de los profesores, que con la mejor buena fe han adoptado el sistema educativo anterior, para seguir aplicándolo de buena gana, y sin la menor duda seria: ¿cómo crees que se lo tomarán, cuando oigan hablar de proyectos de los que estén excluidos $y$, además, beneficio naturae, de exigencias que superen con mucho sus mediocres capacidades, de esperanzas que no tienen resonancia en ellos, de luchas cuyo grito de guerra ni siquiera comprenden, y en las que intervienen sólo como masa sorda, recalcitrante, plúmbea? Por lo demás, ésa tendrá que ser, sin exageración, la posición inevitable de la mayoría de los profesores en las escuelas superiores...

Friedrich Nietzsche. El porvenir de nuestras instituciones.

\section{Introducción}

La cultura política colombiana se ha caracterizado por privilegiar los intereses privados por encima de los públicos. La debilidad del Estado ha permitido que en el país históricamente se hayan constituido gremios, corporaciones, asociaciones y ejércitos privados con poder económico, social y polí-

\footnotetext{
${ }^{1}$ Este artículo se construyó en su parte histórica con base en una ponencia presentada en el XI Congreso de Historia de Colombia realizado en Bogotá en el mes de agosto del año 2000.
}

tico que le disputan permanentemente el poder coercitivo y el ejercicio de la fuerza. Juego político del cual las instituciones no escapan, por el contrario, en los estudios de los diferentes entes públicos y privados -en este ensayo sólo se hará alusión a las instituciones universitarias- se percibe como éstos funcionan haciendo eco a esta realidad. Particularmente, el sistema educativo y la universidad colombiana son un claro ejemplo de la escasa apropiación de lo público por parte de la sociedad. Entiendo por público, lo abierto y el lugar de reconocimiento del otro; es decir el espacio en el cual los hombres se reconocen como seres 
sociales y libres a través de la acción política ${ }^{3}$. En Colombia, por el contrario la mayoría de las universidades públicas han surgido por intereses particulares, primando las decisiones económicas de las élites locales por encima del interés general, allí lo público está supeditado a lo privado.

Las universidades colombianas atraviesan hoy uno de sus más difíciles momentos, en un período en que se les ha otorgado en alguna medida una autonomía - profundamente limitada a la hora de tomar decisiones financieras y administrativas-, pues las decisiones y los consensos en ellas están afectadas por la crisis política del país y de la sociedad en general. Todos los actores políticos hacen presencia permanente en los claustros universitarios, dificultando cualquier decisión orientada a "modernizar" las instituciones ${ }^{4}$, a esta situación

\footnotetext{
${ }^{3}$ Hannah Arendt. La condición humana. Ed. Paidos. Barcelona. 1996, p. 45. La gran dicotomía público-privado es abordada de manera magistral por Norberto Bobbio, quien no desconoce que los gremios (sociedad civil) pueden adquirir tal poder, hasta el punto de incidir directamente en la sociedad política (lo público), siendo función del Estado ser garante y mediador de esta relación dicotómica. Norberto Bobbio. Estado, gobierno y sociedad. Por una teoría general de la política. Ed. FCE. Bogotá. 2000, pp. 31-32.

${ }^{4}$ La Universidad constantemente se está repensando a si misma y la reforma siempre está presente en sus tareas académicas, en la actualidad esta dinámica coincide con políticas en toda la región de América Latina, (lideradas por organismos internacionales encabezados por Banco Mundial) y que tienen como propósito orientar procesos de regulación de la autonomía universitaria, teniendo en cuenta criterios de calidad, eficiencia y competitividad. Con estos criterios en este último
}

es necesario agregar el clientelismo tradicional de que han sido víctimas desde sus orígenes; los procesos de ajuste fiscal liderados por el capital financiero que las han afectado en sus recursos económicos; y por último la escasa incidencia de las universidades tercermundistas en la nueva dinámica de la "sociedad del conocimiento" que deja por fuera sus precarias investigaciones; todo ello hace de las universidades un espacio que está en el ojo del huracán.

En este panorama político, es en el que se circunscribe la toma de decisiones por parte de la comunidad universitaria del país para plantear una reforma que le permita encarar estos nuevos retos. Los entes encargados de asumir posiciones y orientaciones para el presente y futuro de las universidades no pueden en ningún momento desconocer estos factores, más aún, en una sociedad que insiste cada vez con más fuerza sobre la idea de la globalización, donde la función de las universidades públicas está determinado por el papel social que se les exige para hacerlas via-

período se han realizado reformas educativas en países como Chile, México, Argentina, Brasil y Venezuela. De igual manera se crearon en todos ellos como en Colombia comisiones nacionales para la evaluación y acreditación de Universidades y programas. Esto con el supuesto de hacerle frente a la globalización, en una sociedad que vende cada vez más la idea de que es a través de calidad regulada por el mercado que se crean nuevas sociedades, donde el "conocimiento global" nos hará iguales. Para un comprensión de estas políticas ver: Joseph M. Brical y José Joaquín Brunner. Universidad Siglo XXI. Europa y América Latina. Regulación y financiamiento. Documentos Columbus. París. 2000. bles, situación de la cual la Universidad no se puede abstraer.

Con el ánimo de enriquecer este debate, a continuación se partirá del concepto clásico de Universidad para posteriormente hacer una descripción del proceso de consolidación de las "universidades partidistas" y públicas de mediados del siglo XX en Colombia, constituidas por proyectos de élite, pues se considera que es en este período donde se perfila el actual panorama político de las universidades; y posteriormente se puntualizará sobre el sentido de la autonomía universitaria, su diálogo con la sociedad y su función pública.

\section{La Universidad}

Las universidades del mundo occidental surgen con las ciudades y la urbanización de la sociedad medieval. Es en los Siglos XII y XIII cuando los "gremios universitarios" comienzan ha perfilarse como tales y adquirir vida propia. No obstante, la función docente de carácter religioso impide que esta sea un labor autónoma, por el contrario sus tareas estuvieron profundamente ligadas a los preceptos eclesiásticos que desde un comienzo van ha orientar los designios de las corporaciones universitarias ${ }^{5}$.

A pesar de la dependencia o de la escasa autonomía de las universidades en estos siglos los gremios profesorales poco a poco se fueron distanciando del

\footnotetext{
${ }^{5}$ Jacques Le Goff. Los intelectuales en la Edad Media. Ed. Gedisa. Barcelona. 1990.
} 


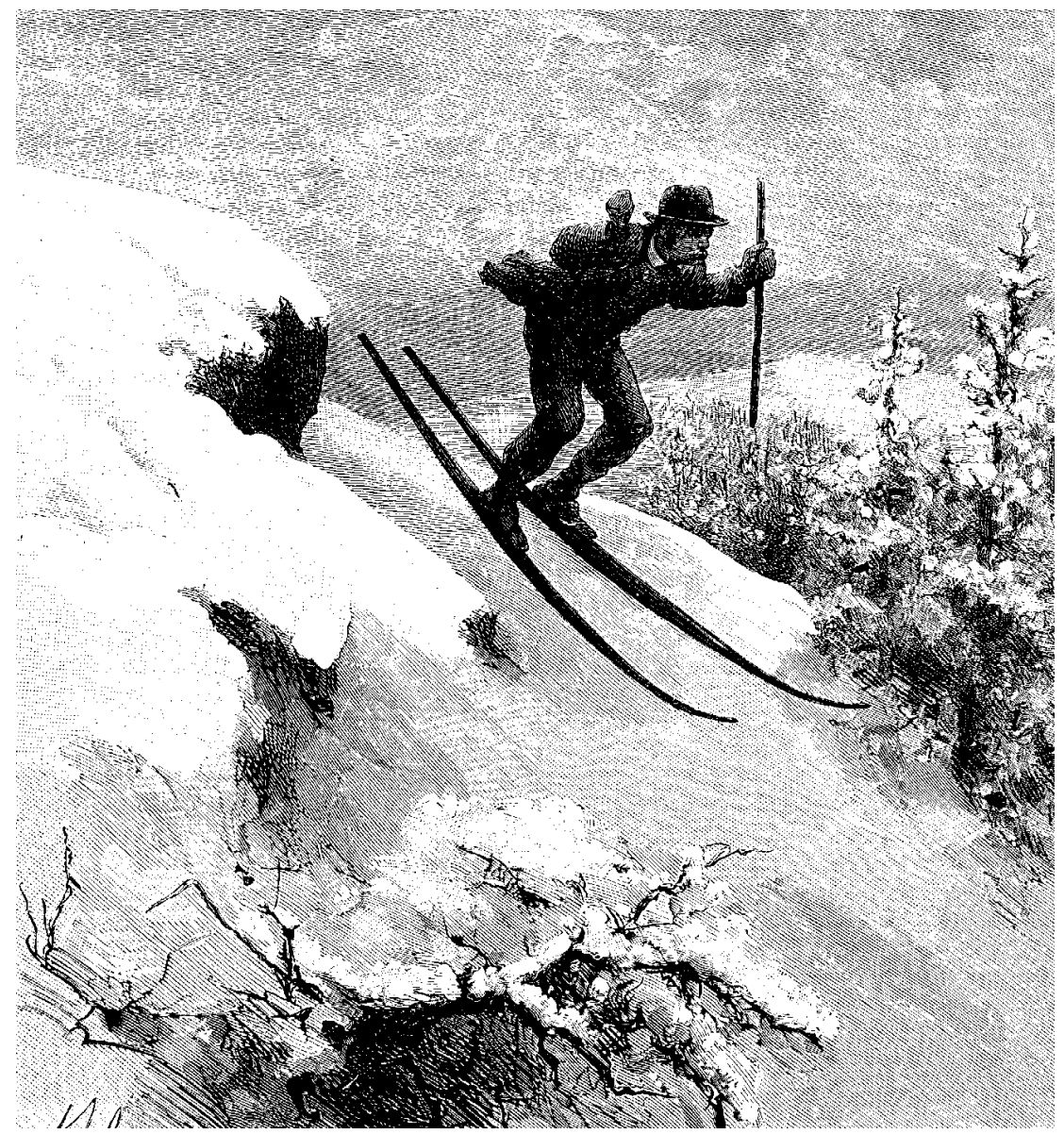

dominio eclesiástico, es así como en el siglo XIII, universidades como la de París, Oxford, Bolonia, adquieren una independencia que les posibilita elegir su propio Canciller. Para lograr dicha autonomía, estudiantes y profesores se vieron obligados a realizar permanentemente huelgas dirigidas a sabotear el comercio de las ciudades que giraba alrededor de las universidades y a entrar en abierta confrontación con los poderes eclesiásticos, situación que en últimas les posibilitó a los universitas adquirir un espíritu de cuerpo, según Emile Durkheim, a identificarse como gremio profesoral ${ }^{6}$.
Otro elemento fundamental en la consolidación de las universidades es su universalismo, el cual según el mismo Durkheim, no se volvió una utopía porque allí se trasmitieran todos los conocimientos, sino porque estudiantes y profesores provenían de diferentes ciudades europeas, lo que posibilitaba que las universidades fuesen ante todo internacionales, aunque el deseo de ser cosmopolitas y enciclopedistas, siempre estuvo presente ${ }^{7}$.

\footnotetext{
${ }^{6}$ Emile Durkheim. Historia de la educación y las doctrinas pedagógicas. Ed. Gedisa. Barcelona, p. 134.

${ }^{7}$ Ibid.
}

Hasta el momento, en este acápite me he referido de manera puntual a dos elementos fundamentales que abarcan el concepto de Universidad: universitas, y autonomía. Pero para ser más amplios en su conceptualización hay que decir que la Universidad está liderada por intelectuales de la cultura. La Universidad es un escenario donde se desarrolla el pensamiento de la sociedad y se reflejan sus desarrollos culturales e intelectuales. En la Universidad, profesores y estudiantes juegan un papel de primer orden, investigan, dinamizan y lideran el campo cultural, por medio de sus estudios y de sus propias estrategias. Quiere decir lo anterior, que por Universidad se entiende una comunidad en la cual sus diferentes estamentos están en continuo diálogo en torno a su función de reproducir el capital cultural de la sociedad. Objetivo logrado a través de la refrendación ante la misma sociedad de la posesión de un capital cultural, simbolizado a través de los títulos universitarios. Es decir, la producción de certificados educacionales "posee un carácter social global, que incluye tanto a la universidad como medio organizacional específico, provisto de una autonomía relativa, como al conjunto del campo cultural de la sociedad"8.

Ahora bien, modernamente la Universidad se ha definido a si misma como una institución que tiene como función principal la docencia, la investigación y la extensión. Tres pilares con los

\footnotetext{
${ }^{8}$ José Joaquín Brunner y Angel Flisfish. Los Intelectuales y las Instituciones de la Cultura. Ed. Granizg. Montevideo. 1983, pp. 97 y 131.
} 
cuales está obligada permanentemente a relacionarse con la sociedad y por ello mismo a "rendirle cuentas".

Las anteriores características o expectativas de la Universidad, deben ser analizadas a la hora de pensar, cuál es la relación de las universidades "modernas" con la sociedad y las actuales propuestas de reforma, sin que su concepto de autonomía pierda vigencia. Autonomía que en los tiempos modernos entendieron los estudiantes liberales de Córdoba como la posibilidad de que las universidades se gobernasen a sí mismas, como en su momento lo plantearon esos profesores medievales, profundamente identificados como gremio, aunque cada vez más secular, pero no por ello más moderno (¿democrático?).

En Colombia, las universidades no han surgido como propuestas independientes de la sociedad, por el contrario sus orígenes obedecen claramente a intereses partidistas y locales (durante el siglo XIX y hasta mediados del XX vinculadas a los partidos tradicionales y durante los años sesenta y setenta a partidos de izquierda), propios de la cultura política colombiana, caracterizada por la fortaleza de los gremios que la convierten en una sociedad "corporativista" en la que lo público pasa a un segundo plano. Allí la autonomía universitaria se pierde y lo público se diluye. Lo cual no quiere decir que en ellas no se hayan dado procesos culturales y sociales que en un diálogo con la sociedad favoreciesen la "modernización" del país, expresiones manifestadas en las décadas del 60 y 70 cuando los estudiantes universitarios marcharon al unísono con los movimientos sociales de la época. Pero a pesar de sus "orígenes" es necesario que las universidades entren en una nueva dinámica que les posibilite ser viables. No obstante, no se puede olvidar que estos orígenes partidistas o gremiales -que las ha convertido en muchos casos en fortines políticos y clientelistasdificultan un proceso transparente y fácil de "reforma"; esto no quiere decir que no se pueda llevar a cabo una reforma democrática orientada a superar estas dificultades históricas y que el gremio universitario no esté en capacidad de hacer una discusión crítica de su tradicional autonomía y prácticas políticas.

\section{Las universidades colombianas: proyectos modernizantes de élite}

Las élites intelectuales han confirmado con la creación de diferentes proyectos educativos y de Universidad, la tesis de utilizar la educación para lograr imponer su ideología. De esta manera surgen diferentes universidades en la historia republicana que representan claramente al partido liberal y al confesionalismo de la institución eclesiástica y del partido conservador. La Universidad Nacional, fundada durante el Olimpo Radical en el año de 1876; el Externado ${ }^{9}$ de los liberales radicales, creada en 1886 , como respuesta a la conservatización y recatolización de la edu-

\footnotetext{
${ }^{9}$ Universidad Externado de Colombia. 1886-1986. Cien años de educación para la libertad. Ed. Universidad Externado. Bogotá. 1989.
}

cación; la Universidad Libre ${ }^{10}$ de 1923 en plena hegemonía conservadora, herencia del mismo radicalismo liberal, y con Benjamín Herrera como gestor; la Escuela Normal Superior de los liberales reformistas; y la Universidad de Medellín ${ }^{11}$, constituida en 1950, como reacción a la contrarreforma conservadora; son ejemplos que representan claramente las respuestas de los liberales a los conservadores en el campo de la educación superior.

La Escuela Normal Superior, ENS $^{12}$, máxima realización educativa de los liberales al lado de la construcción de la Ciudad Universitaria y la centralización de la Universidad Nacional, reflejan ampliamente la función dada a la educación, en este caso a la superior. La ENS desde sus orígenes en el año de 1936 se caracterizó por entrar en abierta oposición con los postulados tradicionales de la educación confesional, que conciliaba los saberes tradicionales y católicos con los avances modernos. El ambiente radical que se vivía en 1936 dio vida a una institución de carácter mixto, lo que de entrada la ponía en abierta oposición a las costumbres católicas; aún más, las creencias religiosas que solamente se habían estudiado como dogma ca-

\footnotetext{
${ }^{10}$ Universidad Libre. Libro de Oro. Santafé de Bogotá. 1995.

${ }_{11}$ Consuelo Posada y José Barrientos. Fundación Liberal de la Universidad de Medellín. UCC. Medellín 1997.

${ }^{12}$ Martha Cecilia Herrera y Carlos Low. El Caso de la Escuela Normal Superior. Una historia reciente y olvidada. Ed. UPN. Santafé de Bogotá. 1994. José Francisco Socarras. Facultades de Educación y Escuela Normal Superior. Su historia y aporte científico, humanístico y educativo. Ed. La Rana y el Aguila. UPTC. Tunja. 1987.
} 
tólico fueron estudiadas en esta institución, desde una mirada sociológica y neutral.

Con la ENS, el Estado liberal no sólo tenía por objeto llevar a la práctica una escuela laica, también quería estatalmente controlar más la formación de docentes, una herramienta tan importante a la hora de masificar su ideología liberal, centralizadora, democratizadora y nacionalista. Su desmonte durante el gobierno de Laureano Gómez y división en dos universidades, una femenina y la otra masculina -Universidad Pedagógica Nacional Femenina, con sede en Bogotá y la Universidad Pedagógica y Tecnológica de Colombia en Tunja-, de marcadas tendencias confesionales demuestra hasta donde las instituciones educativas estuvieron filtradas por los proyectos partidistas ${ }^{13}$.

Los conservadores y la institución eclesiástica hacen lo propio, pues tienen en la Universidad Pontificia Javeriana, reabierta por los jesuitas en 1932; en la Universidad Católica Bolivarina de Medellín, fundada en 1936; y en la Universidad de los Andes, creada en 1948; unos intereses marcadamente tradicionales. Las dos primeras confesionales, respuesta contundente a las políticas liberales de secularización de la educación; la otra, la Universidad de los Andes -en plena contrareforma política- se destaca como proyecto de la

\footnotetext{
${ }^{13}$ Para una comprensión de este proceso véase de Absalón Jiménez Becerra y Helwar Hernando Figueroa. Historia de la Universidad Pedagógica Nacional. Una institución formadora de docentes. Universidad Pedagógica Nacional. Sin publicar.
}

élite modernizadora pero de ideología conservadora.

La fundación de la Universidad de los Andes, como lo expresa uno de sus historiadores oficiales, Daniel Arango ${ }^{14}$, surge de la necesidad que tenía la élite bogotana de tener un espacio académico para formación superior que se encargase de educar a la nueva dirigencia del país. De esta manera se pretendía formar profesionales con grandes capacidades académicas y con un capital cultural alto, en este caso a ingenieros -que terminan sus estudios en las Universidades de Illinois, Texas y Pittsburg- capaces de liderar procesos de modernización tecnológica en el país. A la creación de la Universidad de los Andes, liderada por los egresados del Gimnasio Moderno y con estudio en Estados Unidos, es necesario añadirle el financiamiento de la Asociación Nacional de Industria (ANDI) por medio de Hernán Echavarría, la familia Obregón y Nicolás Gómez Dávila (presidente de la junta directiva del Banco de los Andes) y los socios del Jockey Club ${ }^{15}$.

A pesar de las connotaciones profundamente partidistas en la fundación de universidades pú-

\footnotetext{
${ }^{14}$ Daniel Arango. Los Primeros Diez años de la Universidad de los Andes. Ed. Uniandes. Santafé de Bogotá. 1998.

${ }^{15}$ El financiamiento para los estudiantes que salían del país se logró por medio de becas otorgadas principalmente desde el Instituto Colombiano de Especialización Técnica en el exterior, ICETEX, del cual Gabriel Batancur era uno de sus más importantes directivos. Estas relaciones como lo relatan sus fundadores favorecieron que este establecimiento otorgara fácilmente las becas para estudiar en el exterior. Gabriel Betancur, organizador
}

blicas y privadas [públicas cuando se está en el poder político y privadas cuando no] en la década del treinta y cuarenta, se presenta una nueva tendencia que vale la pena analizar: el surgimiento de universidades regionales de carácter "público" - departamentales-, al lado de la cada vez más importante fundación de universidades privadas. Los proyectos de las universidades departamentales obedecen a intenciones un tanto diferentes a las meramente partidistas, ya que dicen representar los anhelos de toda una comunidad por encima de los intereses particulares [Es necesario aclarar que este discurso oficial expresado por la élite, y en sus inicios no refleja el interés general, el cual sólo va a ser manifestado tardíamente cuando las universidades se masifican]. Con estas universidades, las élites ven la posibilidad de crear procesos modernizadores en sus regiones; además, como lo expresan en los motivos de creación de las mismas, procuran crear identidades regionales con el ánimo de hacerle contrapeso a las existentes en Bogotá.

En este sentido resulta muy útil referirse a las identidades regionales que existen alrededor de la Universidad de Antioquía. Esta universidad es considerada por los antioqueños como su alma máter, en su formación y proyección las élites han consignado ingentes esfuerzos; con la participación de las figuras más insignes de la región. La historiadora

desde el ministerio de educación del Fondo Universitario Nacional, FUN; fue también Secretario General de la Asociación Nacional de Industriales, ANDI. 
María Teresa Uribe ${ }^{16}$ y su equipo de trabajo en el libro: Universidad de Antioquía. Historia y Presencia, publicado en 1998, realizan un extensa investigación que da cuenta de la importancia de esta universidad para la élite de Medellín. Remontan sus orígenes hasta 1805 y describen a través de su historia el desarrollo económico, social y cultural de Medellín. Para María Teresa Uribe, aunque la Universidad estuvo dominada por los dos partidos tradicionales, en momentos diferentes, este es un proyecto de tradición eminentemente antioqueño, el cual supera ampliamente la pertenencia a uno de los dos partidos.

No obstante, el interés de estos investigadores de mostrar una Universidad aglutinante en términos globales, no desconocen las tensiones existentes en los periodos más conflictivos de la vida política del país. Tensiones que posibilitan que de la Universidad de Antioquía se desprendan dos instituciones más: la Universidad Católica Bolivariana en 1936 y la Universidad de Medellín en 1950. "...se reafirmaba una especie de tradición que, con contadas excepciones, venía desde el siglo XIX: las hegemonías político-partidistas en la universidad pública conducían a los enemigos de turno a buscar alternativas privadas de educación para sus hijos. El seminario y el colegio de los jesuitas fueron los recursos con que contaron los conservadores en el siglo XIX para librarse de las influencias de los gobiernos

\footnotetext{
${ }^{16}$ María Teresa Uribe (Coordinadora). Universidad de Antioquía. Historia y Presencia. Ed. Universidad de Antioquía. Medellín. 1998.
}

radicales y sus experimentos pedagógicos"17.

El enfrentamiento partidista de liberales y conservadores en el campo de la educación pública tiende a modificarse a mediados del siglo XX pues los partidos tradicionales dejan de ver en éste un espacio de enfrentamiento ideológico, y formador de ciudadanos. La urbanización del país y las políticas de planificación educativa $^{18}$-emanadas de organismos internacionales- presionan una modernización liderada por élites regionales y el sector privado. En esta dinámica, las élites pasan a cumplir un papel modernizante en el campo regional fortaleciendo las universidades secciónales, en las cuales se privilegia los saberes técnicos, por encima de los humanísticos, haciendo eco a la racionalidad instrumental, atacada tan apasionadamente en los años sesenta y setenta por los movimientos sociales de la época.

Las políticas centralizadoras en el campo de la educación y que caracterizaron a los gobiernos

Matrículas concentradas en el sector privado

\begin{tabular}{|c|c|c|c|c|c|}
\hline Periodo & Total & $\begin{array}{c}\text { Sector } \\
\text { público }\end{array}$ & $\%$ & $\begin{array}{c}\text { Sector } \\
\text { privado }\end{array}$ & $\%$ \\
\hline 1935 & 4.137 & 2.248 & $72 \%$ & 1189 & $28 \%$ \\
\hline 1966 & 50.035 & 28.305 & $54 \%$ & 21.730 & $46 \%$ \\
\hline 1980 & 271.650 & 100.803 & $37 . \%$ & 170.847 & $63 \%$ \\
\hline
\end{tabular}

Fuente: estadísticas del Icfes.

${ }^{17}$ Ibid., p. 335.

18 Gabriel Betancur Mejía (compilador). Documentos para la Historia del planeamiento Integral de la Educación. Vol. Introductorio. Ed. UPN. Bogotá. 1984. republicanos comenzaron a ser superadas por las propuestas regionales de educación superior y por la cada vez más notoria presencia del sector privado en las instituciones de educación superior.

De esta manera la educación dejó de ser un arma ideológica fundamental de los partidos tradicionales, y se convirtió durante el Frente Nacional, en un sector secundario dentro de las políticas estatales, a pesar de que en este mismo período hubo una disminución del analfabetismo, propiciado desde el Estado y liderado por los nacientes organismos internacionales que buscan de esta manera el desarrollo de América Latina. Pero la inusitada participación del sector privado en la educación superior que llegó a tener una matrícula del $63 \%$ del total nacional en 1980 , frente a un $28 \%$ en 1935 , obedece a la falta de un interés real por parte del Estado para masificar la educación de una forma verdaderamente democrática. 
panorama educativo el Estado por medio de diferentes reformas (1958, 1964, 1968, 1980) intentó organizar un sistema coherente y moderno de la Educación Superior ${ }^{19}$. Objetivo que no logró, por el contrario, la masificación generó una educación heterogénea, fragmentada, profesionalizante y de baja calidad.

\section{Las universidades regionales como proyectos de élites locales}

Las historias de las universidades regionales en Colombia creadas principalmente en los años cuarenta evidencian claramente que han surgido como proyectos regionales de las burguesías locales. Son pensadas con el ánimo de establecer comunidades académicas modernas que tiendan a desarrollar la región en términos económicos y culturales. En este contexto se puede ubicar el origen de la mayoría de las universidades departamentales, las cuales surgen masivamente a mediados de la década del cuarenta en pleno desarrollo económico de las regiones. Pero a pesar de que estas universidades sean públicas, allí se concentran los intereses particulares de las élites regionales, donde lo público nuevamente vuelve a hacer utilizado de manera privada para el desarrollo económico de la región, lo cual no quiere decir que en el proceso de consolidación de estas

\footnotetext{
19 Absalón Jiménez Becerra y Helwar Hernando Figueroa. "Políticas educativas en la educación superior. 1952-1992". Revista Colombiana de Educación. № 3839. Universidad Pedagógica Nacional. Bogotá. 1999.
}

universidades, los sectores populares no hayan logrado acceder a éstas. Por el contrario, en los años 60 y 70, gracias a la masificación universitaria, las universidades departamentales y las nacionales son objeto de permanentes intervenciones de la fuerza pública porque en ellas se consolidaron procesos sociales "radicales" en los cuales la "comunidad educativa", los movimientos sociales y los grupos políticos de extrema izquierda hicieron presencia permanente. Problemática que por no ser objeto de este escrito no se desarrollará, sin embargo, es necesario decir con Leo Kofler que los postulados sociales promulgados por las sociedades burguesas son realizados por medio las presiones sociales de los excluidos del poder ${ }^{20}$.

En los años cuarenta se fundaron en este proceso las universidades de los departamentos del Atlántico, Boyacá, Santander y Valle; zonas que comienzan a caracterizarse por el desarrollo industrial, campo de crecimiento acrecentado en la postguerra por la política de sustitución de importaciones. Al igual que las Universidades del Tolima y Caldas, que tienen en el desarrollo económico originado por el comercio del café su mayor motor.

\footnotetext{
${ }^{20}$ Así lo expresa Leo Kofler: “...el más hermoso fruto de la secular lucha burguesa, la forma democrática de organización y de vida de la actual sociedad, en modo alguno ha sido obra de la burguesía -en especial en lo que se refiere a su consumación práctica-, sino ante todo de las clases no burguesas, de la pequeña burguesía y del proletariado". Leo Kofler. Contribución a la historia de la sociedad burguesa. Ed. Amorrortu. Buenos Aires. 1971, p. 445.
}

La Universidad del Valle, fundada en 1945, es un buen ejemplo de esta situación. Arcadio José Guzmán y Luis Aurelio Ordoñez ${ }^{21}$, en su libro: El Origen de la Universidad del Valle y su Contexto Histórico, evidencian claramente este fenómeno. Los autores desde un comienzo explícitan que la Universidad del Valle se crea por la necesidad que tienen los sectores de la burguesía industrial de desarrollar mano de obra calificada y profesional que sea capaz de liderar la industrialización que sufre la región, de la cual la ciudad de Cali es gestora. Industrialización que se da por el desarrollo portuario de Buenaventura, el crecimiento de la industria azucarera, situada a las afueras de Cali y a la economía cafetera de las laderas del Valle del Cauca.

En este mismo sentido, la Universidad Industrial de Santander (UIS), los investigadores Ariel Díaz Osorio y Libardo León Guarín $^{22}$ en su Historia de una Universidad del Medio Siglo: La UIS, evidencian que esta Universidad surge con el espíritu modernizante de la posguerra, a finales de la década del cuarenta. Surgimiento liderado por una élite que busca crear los mecanismos para industrializar la región del oriente, respondiendo a las políticas de sustitución de importaciones. Políticas -explican los autores- que responden al proteccionismo de Estado y al de-

\footnotetext{
${ }^{21}$ Arcadio José Guzmán y Luis Aurelio Ordoñez. El Origen de la Universidad del Valle y su Contexto Histórico. Ed. Universidad del Valle. Cali. 1995.

${ }^{22}$ Ariel Díaz Osorio y Libardo León Guarin. Historia de una Universidad del Medio Siglo. La UIS. Ed. UIS. Bucaramanga. 1996.
} 
sarrollo capitalista, promulgado por el Keinesianismo y posteriormente por la CEPAL. La creación de la UIS responde al propósito de crear sentimientos de regionalismo, afirman Díaz y León, para superar la hegemonía del centro del país. Regionalismo acrecentado por el fortalecimiento de la industria petrolera, que creó el interés de una élite local capaz de responder a los nuevos designios petroleros.

La fundación de estas universidades departamentales, como ya se ha descrito, no favorecieron nacionalmente la consolidación de un sistema universitario coherente, por el contrario sus fundaciones, unidas al crecimiento desbordado de instituciones de educación superior desarrollaron un sistema acéfalo.
Por otra parte se observa que en la década del cuarenta hay un aumento significativo del número de universidades departamentales, que pasaron de cinco en las primeras tres décadas a 25 para el año de 1967. De las cuales 15 son oficiales y tuvieron un aumento destacado en los años cuarenta. Por último se destaca la superación del número de universidades privadas, frente a las públicas en el período 19511967, donde del total de universidades existentes para el año de 1967 , el $58 \%$, son privadas. Situación que es desbordada para el año de 1980, pues de un total 201 instituciones de educación superior, el $75 \%$ son privadas.

El investigador uruguayo, Germán Rama, ya en 1968 demostraba la dispersión del sistema

Fundación de las universidades colombianas

\begin{tabular}{|l|c|c|c|c|c|}
\hline Periodo & $\begin{array}{c}\text { Número } \\
\text { universidades }\end{array}$ & Oficiales & Privadas & Bogotá & $\begin{array}{c}\text { Regio- } \\
\text { nales }\end{array}$ \\
\hline Siglo XIX & 5 & 4 & 1 & 2 & 3 \\
\hline $1900-1933$ & 10 & 4 & 6 & 5 & 5 \\
\hline $1941-1950$ & 18 & 10 & 8 & 7 & 11 \\
\hline $1951-1967$ & 43 & 18 & 25 & 18 & 25 \\
\hline $1968-1980$ & 201 & 51 & 151 & - & - \\
\hline
\end{tabular}

Fuente: estadísticas del Icfes.

Del anterior cuadro interesa destacar que antes de 1900 solamente existieron con cierta discontinuidad, producto de los conflictos políticos, dos universidades en Bogotá y otras tres ubicadas en Cartagena, Medellín, Popayán; y que de las cinco existentes en todo el país, cuatro eran oficiales. universitario, comparando la concentración de la matrícula por regiones y fechas de fundación, evidencia que sólo dos de las universidades creadas antes de 1900 poseen una matrícula significante ${ }^{23}$. La Universidad Nacional de Colombia con 11.082 estudiantes, y la Universidad de Antioquía con 3.794. Las Univer- sidades del Cauca y Cartagena, tienen un promedio superior a 1000 estudiantes. De esta fecha en adelante, hasta la publicación de su investigación en 1968, demuestra como hay un descenso en el número de estudiantes en la matrícula de las universidades regionales.

Rama concluye -teniendo en cuenta la situación de las instituciones de educación superior colombianas en el contexto latinoamericano, pero fundamentalmente las cifras nacionales- que las universidades colombianas, principalmente las regionales, no concentran a un número significativo de estudiantes, pero por otra parte y quizás la más importante de las conclusiones es que la creación de las mismas no estuvo acompañada de un proceso lógico de desarrollo del sistema educativo. Situación que explícita a través del análisis de la fundación de la Universidad de Córdoba, 1965. Universidad que se funda por el interés de la élite local que tiene en consolidar la expansión ganadera principal motor de la economía de la región, de ahí que las primeras carreras estuvieran directamente relacionadas con este sector productivo (Zootecnia y veterinaria) ${ }^{24}$. A pesar de ello, para Rama no es comprensible como en una región que tiene un analfabetismo del $51.9 \%$, se privilegia la creación de una universidad, que capta la mayoría de los recursos

\footnotetext{
${ }^{23}$ Germán W. Rama. El Sistema Universitario en Colombia. Ed. Universidad Nacional de Colombia. Bogotá. 1970, pp. 44-47. 24 José Manuel Vergara. Historia de la Universidad de Córdoba. Ed. Universidad de Córdoba. Bogotá. 1999.
} 
en inversión educativa ${ }^{25}$. Vale la pena decir que este caso no es ajeno a la situación global del sistema educativo nacional. Ya es un hecho comprobado que un gran porcentaje de los recursos invertidos en el sector educativo fueron a parar al sector universitario, en detrimento de la educación básica, primaria y secundaria, y fundamentalmente de las regiones rurales.

Aún más, siguiendo a Rama, la matrícula para el año de 1968 se mantiene concentrada en Bogo- ha mantenido en un promedio del $45 \%{ }^{26}$.

El Estado en la década del cincuenta veía en la creación de instituciones o aparatos burocráticos más ventajas que decretar políticas o leyes que propugnaran por un desarrollo coherente del sistema educativo. Políticas necesarias que habían sido desde mediados del cincuenta propuestas en los diferentes seminarios o discusiones entorno a la planeación educativa. La gran cantidad de aparatos burocráti-

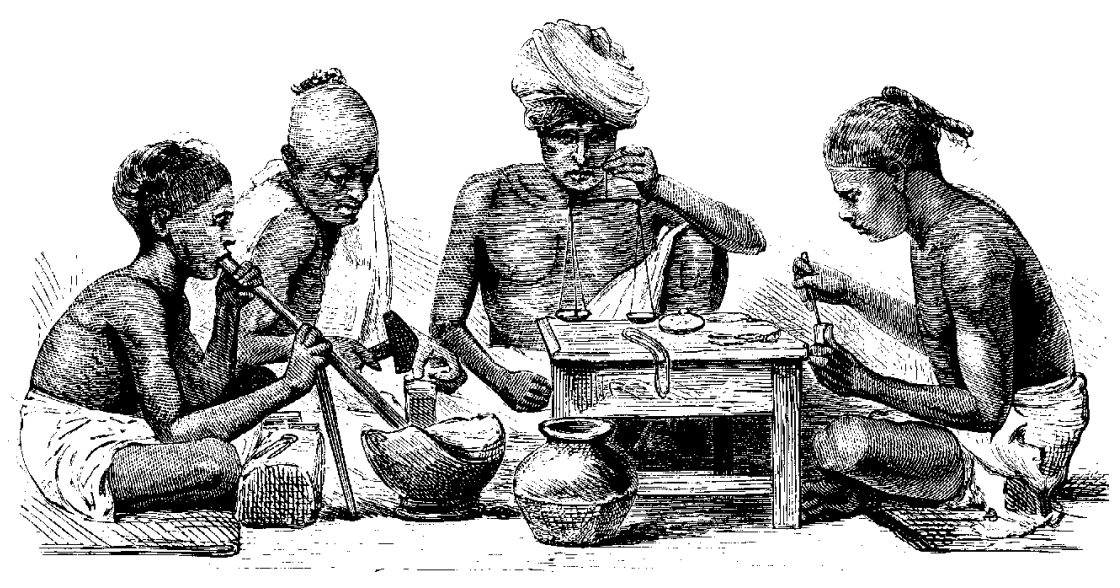

tá con una participación del 54\%, esto evidencia que la creación de universidades departamentales no está acompañada de una mayor participación de la matrícula en las mismas. Las ciudades de Barranquilla, Cali y Medellín participan con el $26 \%$ de total de la matrícula del país, y sólo el $19.3 \%$ es utilizada por los ciudadanos del resto del país. De esta fecha hasta mediados de los años ochenta el porcentaje de la concentración de matricula en educación superior en Bogotá se

\footnotetext{
${ }^{25}$ Germán Rama. Op. cit., p. 47.
}

cos (ICETEX, FUN, ASCUN, SENA, ICFES, COLCIENCIAS; $Y$ los organismos circunscritos directamente al Ministerio de Educación), expresan la difícil consolidación de un sistema planificado de educación superior y más bien fortalecen políticas de descentralización administrativa, acompañadas del clientelismo tradicional que encuentra en estas instituciones su nicho natural. Al respecto Rama sostiene que las políticas promulgadas estamentalmente son en algunos casos contradictorias y meramente indicativas y no obligan a las universidades oficiales o privadas a llevarlas a cabo $^{27}$.

En conclusión, las universidades colombianas, en sus orígenes estuvieron fuertemente vinculadas a los partidos tradicionales; y las regionales de medio siglo - de carácter público- a intereses de las elites locales. Orígenes que las convierten en instituciones donde lo público pasa a un segundo plano, pues su función pública está atravesada por el interés particular, en el caso de las universidades partidistas; y en el de las universidades regionales reflejan el desarrollo económico de las élites.

Pero a pesar de que las universidades públicas tienen estos orígenes, no se puede negar que en ellas se han desarrollado procesos culturales que las convierten en espacios académicos y modernizantes que han posibilitado, en alguna medida, una lectura secular de la sociedad colombiana y a través del acceso de sectores populares a ésta también han contribuido a democratizar la vida nacional. En este sentido y para que las universidades públicas sigan cumpliendo estas funciones, se expone a continuación algunos planteamientos claves a la hora de vislumbrar sobre cuál puede ser el futuro de las Universidades públicas y el papel de la autonomía en un momento en que nuevamente se plantea su reforma.

\footnotetext{
${ }^{27}$ Germán W. Rama. Op. cit., p. 50.
} 


\section{Reforma, autonomía universitaria y lo público}

El escenario de saber por excelencia se enfrenta al reto de organizar un saber propio, precisamente en este tiempo donde el conocimiento se identifica con la técnica y el desarrollo tecnológico es transformado en poder - encargado de excluir y marginar a culturas y sociedades tomando como parámetro su mayor o menor avance en este campo-. El conocimiento despunta el máximo valor universal y la necesidad de ingresar a esa sociedad global se presenta ahora como un problema político de primer orden ${ }^{28}$. Ante esta realidad, las universidades de los llamados países en vías de desarrollo están en la obligación de reflexionar acerca de esta situación apremiante, con el fin de proyectarse y proponer salidas dignas encaminadas a orientar la acción presente en la perspectiva de un sentido deseado. Teniendo en cuenta lo anterior una reforma universitaria -en Colombia-que apunte a estos nuevos retos requiere tener presente los siguientes lineamientos:

\section{Superación de su gremia-} lismo: La Universidad como gremio de iniciados debe modificar sus actitudes frente a la sociedad y abrirse a ella. El gremio de las universidades, que desde un comienzo realizó ritos corporativos de iniciación, (por ejemplo la licencia entregada solemnemente después de su lección inaugural inceptio, acompañada de

\footnotetext{
28 Taichi Sakaiya. Historia del futuro. La sociedad del conocimiento. Ed. Andrés Bello. Santiago de Chile. 1995.
}

una ceremonia caballeresca con birrite y toca), crea un espíritu de cuerpo que impide que elementos externos modifique sus reglas. Desde la época en que las universidades buscaron distanciarse de la institución eclesiástica su autonomía las ha vuelto un tanto displicentes con su entorno social. No obstante, en la actualidad la Universidad, cada vez se debe más a la sociedad, hasta el punto que hoy, ésta última constantemente le "exige cuentas" o ve en ella la encargada de proponer, en momentos de crisis, salidas académicas y objetivas a los diferentes conflictos sociales y políticos. De ahí que su condición corporativa haya entrado en un proceso de desmonte... ¿modernización? Pues como lo han demostrado estudios recientes, la Universidad ha quedado rezagada de su función social y de los principales desarrollos científicos, que hasta hace unos años se venían presentado en su interior y que justificarían ideológica y académicamente su existencia. Si su función investigativa no se cumple ¿Cuál sería su razón de ser?

Pero, aún más, para el caso colombiano, un país alejado de las investigaciones tecnológicas de punta, las discusiones entorno a la autonomía universitaria han demostrado que su ejercicio es muy limitado y está atravesado por intereses partidistas y el corporativismo de profesores y estudiantes a la manera medieval (ambas tradiciones, que aún hoy parecen, estar presentes). Basta con recordar como los orígenes de las universidades públicas y privadas en el país han estado profundamente marcadas por intereses de índole econó- mico y político, este hecho unido a la propia tradición universitaria de Occidente las convierte en un "fortín" de difícil acceso.

La autodenominada autonomía de las universidades desde sus orígenes, en la sociedad medieval y vuelta consigna en el manifiesto de Córdoba por "estudiantes liberales" requiere ser pensada de una manera más objetiva para superar su corte gremialista y liberal. Pues no podemos caer en una mera defensa de ésta por el solo hecho de mantener unos privilegios adquiridos, posiblemente, en este momento, no tan merecidos. De ahí el llamado urgente que hace Guillermo Hoyos para llevara a cabo una discusión democrática de la función pública de la Universidad: "es urgente que la Universidad Pública misma logre presentar públicamente aquellas razones por las cuales cree que la educación pública sigue siendo una institución absolutamente necesaria para el progreso del país, es decir, que sin ella nuestro Estado de derecho democrático, ni nuestra sociedad pueden aspirar seriamente a lo que quieren ser"29.

2. Función pública: Una reforma de las universidades debe tener en cuenta que defender la autonomía, no implica modernamente una defensa corporativista, sino la posibilidad de hacer de las instituciones universitarias campos abiertos para el conocimiento y el continuo diá-

\footnotetext{
${ }^{29}$ Guillermo Hoyos Vásquez. Lo público de la Universidad Pública. Unidad de prospectiva y políticas educativas. Sin publicar.
} 
logo con la sociedad. Quiere decir que las universidades deben buscar las herramientas pedagógicas y políticas que posibiliten el acceso a la mayoría de los ciudadanos, para superar de esta manera su condición gremialista y en últimas excluyente, que limita el acceso a las mayorías y fácilmente las saca del sistema. De esta manera las universidades realmente podrían cumplir su función pública, pues estarían en la posibilidad de permitir el acceso de la mayoría de la población a la educación superior; y por otro lado aportarían en la construcción de la ciudadanía a través de debates abiertos a toda la sociedad. En este sentido, resulta profundamente enriquecedor traer nuevamente a escena el pensamiento de Anna Arendt para quien lo público sólo puede ser entendido como un lugar abierto donde el ciudadano se vuelve actor y es reconocido como tal por su participación en las decisiones sociales, en este caso tendría la necesidad apremiante de hacer públicos sus planteamientos sobre Universidad y el destino de ésta. Pero esta ciudadanía evidentemente no podría limitarse a un ejercicio de representación excluyente, por el contrario debe enfrentarse de manera crítica a los designios de un modelo que vende la idea de una corporatización de la sociedad, sazonada con el consumo y la individualización posmoderna del individuo ${ }^{30}$.

\section{Desideologización de las políticas neoliberales: Por la}

\footnotetext{
${ }^{30}$ Daniel Libreros Caicedo y Helwar Hernando Figueroa. Cultura, economía política y educación. Unidad de prospectiva y políticas educativas. Sin publicar.
}

manera como se han creado y organizado las universidades, particularmente las colombianas, ellas requieren una reforma académica, administrativa y financiera que las haga más viables, eficientes y menos clientelistas, obviamente no en los términos propuestos últimamente por el "mercado". Entendido este último, como el que va a posibilitar medir la calidad de las mismas y la elección de las mejores, por los aspirantes que están en la posibilidad de entrar en el proceso -en el lenguaje mercadológico, clientes-de la "libertad de elegir". Quiere decir lo anterior que no se puede caer en la falsa premisa del neoinstitucionalismo [continuación del modelo neoclásico de la escuela de Chicago que parte de la tesis de que las personas se organizan para obtener el máximo de bienestar a través de la creación de los mercados y de la competencia] que propone la búsqueda de la calidad, la eficiencia, la competencia reguladora, en un contexto liderado por la econometría, como elementos fundamentales para lograr la máxima ganancia, donde el Estado se limitaría a favorecer el funcionamiento del mercado. Logro obtenido por medio de una economía racional, que impide cualquier margen de perdida $^{31}$.

\footnotetext{
${ }^{31}$ El profesor Daniel Libreros en sus últimos trabajos explica como el neoinstitucionalismo toma de la economía neoclásica un punto que es fundamental: abandona un sentido interpretativo de la sociedad, a la manera de Adam Smith y David Ricardo -centrado en las explicaciones sociales-y pasa a un problema de estadística, de funcionamiento de precios, de mercados. Es decir diluye los actores de la sociedad en función de estabilizaciones macro... Esta forma de análisis se ha convertido en una concepción del mundo, es
}

Finalmente se insiste en que la autonomía universitaria no sea gremialista (partidista, privada y profesoral), sino una puerta para el conocimiento y que la reforma académica, al lado de la administrativa, esté orientada para que la mayoría de las personas puedan acceder a la Universidad y el sistema no las saque. Lo cual quiere decir que la reforma de las universidades debe estar pensada para que éstas sean realmente democráticas y posibiliten la adquisición por parte de todos los ciudadanos de conocimientos críticos. Es decir, que impidan que éstos sean trasmitidos sin discusiones críticas, que sólo tienen cabida en las sociedades "virtuales".

En cuanto a la reforma administrativa, esta evidentemente no pude desconocer los criterios de eficiencia y coordinación de los procesos que la hagan más viable y funcional. Sin embargo, esta reforma por ningún motivo puede estar por encima de los criterios académicos que le dan el norte a las universidades (bús-

una nueva ética del capital, una lógica racional del funcionamiento del capital, apalancada por la privatización de la política y el derecho. Lo que lleva a los teóricos de esta esquema a proponer que es necesario manejar los bienes públicos como si fueran mercados. "Donde los Estados -afirma Libreros- sólo existen para controlar la imperfecciones del mercado, ocasionadas por las externalidades del mismo. Para Buchanan si no existieran externalidades no serían necesarios los estados. La focalización de pobres es un problema de externalidades. La política educativa está mercantilizada para que los pobres entren al mercado y de esa manera expandirlo". Este debate se percibe claramente en las tesis de Eduardo Wiesner Durán. La efectividad de las políticas educativas. Un análisis neoinstitucional. Ed. Tercer Mundo. Bogotá . 1998. 
queda permanente del conocimiento). A pesar de que en América Latina -más que en los países desarrollados- las universidades están, por la misma dinámica de la globalización, cada vez más distantes de la investigación, lo que dificulta su función, pero como lo han demostrado en su larga historia, estas instituciones son un referente que democratiza en alguna medida el conocimiento y es ahí donde son fundamentales para la sociedad. La reforma universitaria requiere mejorar la función democratizadora de la universidad -lo que se impide con una reforma, meramente basada en términos del mercado- no enterrarla. Pues es de todos conocido que por la dinámica del mercado este tiende ha concentrarse y convertirse en un monopolio, que por su misma naturaleza se muestra ideológicamente reproductor de una hegemonía excluyente... ¿moderna?

La educación colombiana está en manos del más del $70 \%$ en el sector privado (caso único en el mundo) y esto por sí mismo no ha redundado en más acceso a ella, lo que ha generado es un sistema anárquico y profundamente estratificado. Donde hay una educación para pobres y otra para ricos. Frente a este sistema de "productiva" (¿pragmática?) y del mercado, el llamado no puede ser otro que impedir este modelo.

\section{Bibliografía}

- Arango, Daniel. Los primeros Diez Años de la Universidad de los Andes, ediciones Uniandes, Santafé de Bogotá, 1998.
- Arendt, Hannah. La condición humana. Ed. Paidos. Barcelona. 1996.

- Asociación Colombiana de Universidades. FUN. Estudios para el planeamiento de la Educación Superior. Régimen legal universitario vigente. Vol. I. Bogotá. 1961.

- Betancur Mejía, Gabriel (compilador). Documentos para la Historia del planeamiento Integral de la Educación. Vol. Introductorio. Ed. UPN. Bogotá. 1984.

- Boвbio, Norberto Estado, gobierno y sociedad. Por una teoría general de la política. Ed. FCE. Bogotá. 2000.

- Bricall, Josep M. y Brunner, José Joaquín. Universidad Siglo XXI. Europa y América Latina. Regulación y funcionamiento. Cinda-Columbbos. París. 2000.

- Brunner, José Joaquín y Flisfish, Angel. Los Intelectuales y las Instituciones de la Cultura. Ed. Granizg. Montevideo. 1983.

- Díaz Osorio, Ariel y León Guarin, Libardo. Historia de una Universidad del Medio Siglo: La UIS, ediciones UIS, Bucaramanga, 1996.

- Durkheim, Emile. Historia de la educación y las doctrinas pedagógicas. Ed. Gedisa. Barcelona.

- Guzmán, José Arcadio y ORdoÑEZ, Luis Aurelio. El Origen de la Universidad del valle y su Contexto Histórico. Editorial Universidad del Valle. Cali. 1995.

- Herrera, Martha Cecilia y Low, Carlos. Los Intelectuales y el Despertar Cultural del Siglo. El Caso de la Escuela Normal Superior. Una historia reciente y olvidada, editorial Imprenta Nacional de Colombia. Santafé de Bogotá, 1994.

- Hoyos, Guillermo. Lo público de la Universidad Pública. Unidad de prospectiva y políticas educativas. Universidad Pedagógica Nacional. Sin publicar.

- Jiménez Becerra, Absalón y Figueroa, Helwar. "Políticas edu- cativas en la educación superior. 1952- 1992". Revista Colombiana de Educación. № 3839. Universidad Pedagógica Nacional. Bogotá. 1999.

- Jiménez Becerra, Absalón y Figueroa, Helwar. Historia de la Universidad Pedagógica Nacional. Una institución formadora de docentes. Sin publicar.

- Kofler, Leo. Contribución a la historia de la sociedad burguesa. Ed. Amorrortu. Buenos Aires. 1971.

- Le Goff, Jacques. Los intelectuales en la Edad Media. Ed. Gedisa. Barcelona. 1990.

- Libreros Caicedo, Daniel y Figueroa, Helwar. Cultura, economía política y educación. Unidad de prospectiva y políticas educativas. Universidad Pedagógica Nacional. Sin publicar.

- Posada, Consuelo y Barrientos, José. Fundación Liberal de la Universidad de Medellín. UCC. Medellín 1997.

- Rama, Germán W. El Sistema Universitario en Colombia. Ed. Universidad Nacional de Colombia. Bogotá. 1970.

- Sakalya, Taichi. Historia del futuro. La sociedad del conocimiento. Ed. Andrés Bello. Santiago de Chile. 1995.

- Vergara, José Manuel. Historia de la Universidad de Cordoba. Ed. Universidad de Cordoba. Bogotá. 1999.

- Uribe de Hincapie, María Teresa (Coordinadora). Universidad de Antioquía. Historia y Presencia. Editorial Universidad de Antioquía, Medellín, 1998.

- Universidad Externado de Colombia. 1886-1986. Cien años de educación para la libertad. Ed. Universidad Externado. Bogotá. 1989.

- Universidad Libre. Libro de Oro. Santafé de Bogotá. 1995.

- Wiesner Durán, Eduardo. La efectividad de las políticas educativas. Un análisis neoinstitucional. Ed. Tercer Mundo. Bogotá. 1998. 